\title{
Article
}

Doi 10.5943/sif/5/1/21

\section{First record of the halophilic fungus Penicilliopsis clavariiformis from Diospyros paniculata}

\author{
Krishnapriya K, Vinjusha N, Anjitha T, Salna N, Arun Kumar TK*
}

The Zamorin's Guruvayurappan College, Kozhikode, Kerala 673014, India

Krishnapriya K, Vinjusha N, Anjitha T, Salna N, Arun Kumar TK 2020 - First record of the halophilic fungus Penicilliopsis clavariiformis from Diospyros paniculata. Studies in Fungi 5(1), 400-405, Doi 10.5943/sif/5/1/21

\begin{abstract}
Penicilliopsis clavariiformis, an ascomycete fungus is reported for the first time from Diospyros paniculata. Conspicuous clavarioid ascomata of $P$. clavariiformis were found emerging out of fruits and seeds of $D$. paniculata growing in a sacred grove in Kerala State, India. Based on morphological and molecular evidences, the identity of the fungus was confirmed.
\end{abstract}

Key words - antibacterial - antifungal - biodiversity - clavarioid - Ebenaceae - Kerala

\section{Introduction}

Diospyros paniculata Dalzell (Ebenaceae) is a medium-sized tree with a soft and rather heavy bark and with whitish-grey wood (Dhongade \& Masram 2012). The tree grows in moist deciduous to evergreen forests of Peninsular India (Ved et al. 2015). It is valued for its medicinal properties. The bark of D. paniculata is used to treat rheumatism and ulcer (Sinha et al. 2009). The gum of the tree shows antifertility effect (Dhongade \& Masram 2012). Dried and powdered fruits of the tree are capable of healing burns, and a decoction prepared from the fruit is used in the treatment of gonorrhoea and biliousness and for cleaning boils (Ved et al. 2015). The plant is known to exhibit antibacterial and antifungal activity (Sinha et al. 2009). At present, D. paniculata is considered as vulnerable according to the IUCN Red List, and this status is attributed to its habitat loss, habitat disintegration, and uncontrolled exploitation for medicine (Ved et al. 2015).

During our investigations on the macrofungal diversity associated with sacred groves in Kerala State, India, interesting clavarioid sulpher yellow fungal fruit bodies were encountered growing out of the fruits and seeds of $D$. paniculata. The fungal fruit bodies were studied. The taxonomic identity of the fungus was investigated and confirmed using morphological and molecular data, and is presented here.

\section{Materials and Methods}

Fruit bodies were collected from the fruits and seeds of $D$. paniculata from a sacred grove of Kerala, India, during August 2018. Microscopic observations were made on materials stained using aqueous solutions of 3\% phloxine, 1\% Congo red and mounted in 5\% aqueous $\mathrm{KOH}$. Reaction of the basidiospores on treatment with Melzer's reagent, and cotton blue was tested. Twenty basidiospores were measured for obtaining the spore dimensions, mean, range of spore quotient (Q, length/width ratio) and its mean value $(\mathrm{Qm})$. Examined collections are deposited at the ZGC herbarium, Kerala, India. Faces of Fungi (FoF) number was obtained, following Jayasiri et al. (2015). 
For DNA extraction from the collected specimens, microwave method was used according to the procedure described by Izumitsu et al. (2012). PCR amplification of the ITS gene region was carried out using the primers ITS1F and ITS4R (Gardes \& Bruns 1993, White et al. 1990). PCR product was purified using ExoSAP-IT treatment. Sequencing was done using BigDye Terminator v3.1 method. BLAST search was done using the NCBI's GenBank nucleotide database with the newly generated sequence (GenBank accession number: MK459552) as the query sequence.

The newly generated sequence was used for the BLAST search in the GenBank database (www.ncbi.nlm.nih.gov). For the phylogenetic analysis, DNA sequences of the ITS dataset were aligned automatically with MUSCLE in MEGA x (Kumar et al. 2018), then manually edited with the same program. The evolutionary history was inferred by using the Maximum Likelihood method and Tamura-Nei model (Tamura \& Nei 1993) in MEGA. The tree with the highest log likelihood (-2100.20) is shown. This analysis involved 11 nucleotide sequences. There were a total of 706 positions in the final dataset.

\section{Results}

\section{Taxonomy}

Penicilliopsis clavariiformis Solms [as ‘clavariaeformis’], Ann. Jard. Bot. Buitenzorg 6: 53 (1887)

Index Fungorum number: IF 596296; FoF number: FoF 08725

Fruit bodies were (emerging from fruits and seeds of $D$. paniculata) up to $9 \mathrm{~cm}$ tall, $2-3 \mathrm{~mm}$ wide, erect to flexuose, unbranched to branched; when branched, two main branches arise from the base, terminal branches irregular, rarely depressed at the centre, thin, narrower towards the tip, glabrous, acute towards the apex, ellipsoid in cross section, solid, not fragile, bright yellow, becoming dull brown on drying, odour unpleasant, spore print yellow (Fig. 1).

Macrochemical test: blackish brown or red in $\mathrm{KOH}$, Pale green in $\mathrm{FeSO}_{4}$ and $\mathrm{FCl}$

Conidiophores 4-9 $\mu \mathrm{m}$ wide, hyaline to pale brown, septate, septations ring like, bulged at two ends, smooth to encrusted, thin to thick walled $(1 \mu \mathrm{m})$. Ramuli $11-25 \times 8-9 \mu \mathrm{m}, 1-3$ per conidiophore, cylindrical to clavate, hyaline, thick walled $(1 \mu \mathrm{m})$. Metulae 15-20 × 5-9 $\mu \mathrm{m}, 2-5$ per ramuli, clavate to broadly clavate, hyaline to pale brown, thick walled (up to $3 \mu \mathrm{m}$ ). Phialides 20-25 × 4-5 $\mu \mathrm{m}$, cylindrical to sub clavate, hyaline. Conidia (6) 7-9 (10) × 5-6 $\mu \mathrm{m}, \mathrm{Q}=1.2-1.8$, $\mathrm{Q}_{\mathrm{m}}=1.59$, sub-globose to ellipsoid, hyaline, eguttulate, densely granular, smooth to finely ornamented, thick walled $(1 \mu \mathrm{m})$, cyanophilic in cotton blue, dextrinoid in Melzer's reagent.

Specimen examined: INDIA, Kerala, Kozhikode, Karanthur, ThurayilKavu Bhagavathy Temple, on fruits and seeds of Diospyros paniculata, 10 August 2018, Krishnapriya K., ZGCKP100, ZGCKP144.

\section{Molecular characterization and phylogenetic analysis}

Sequencing of ITS region of the collection (ZGCKP144) yielded 582 base pairs. BLAST search in NCBI's GenBank nucleotide database using the newly generated sequence resulted in 99\% identity with Penicilliopsis clavariiformis strains (GenBank numbers- MH855432, JN864881, AF033391, EF669714). Phylogenetic analysis of the newly generated ITS gene sequence showed its relation to the members of the genus Penicilliopsis (Fig. 2). Our sequence clustered with relatively good bootstrap support near other $P$. clavariiformis sequences.

\section{Discussion}

Genus Penicilliopsis was erected by Solms in 1887 with P. clavariiformis as the type species. According to Samson \& Seifert (1985), Penicilliopsis is an ascomycete with a phialidic anamorph. Currently, the genus includes 13 species (Index Fungorum 2020). Most members of this genus are characterized by highly branched yellowish ascomata, cylindrical to slightly clavate or swollen metulae with phialides and smooth to echinulate or irregularly roughened conidia that are generally ellipsoid. 


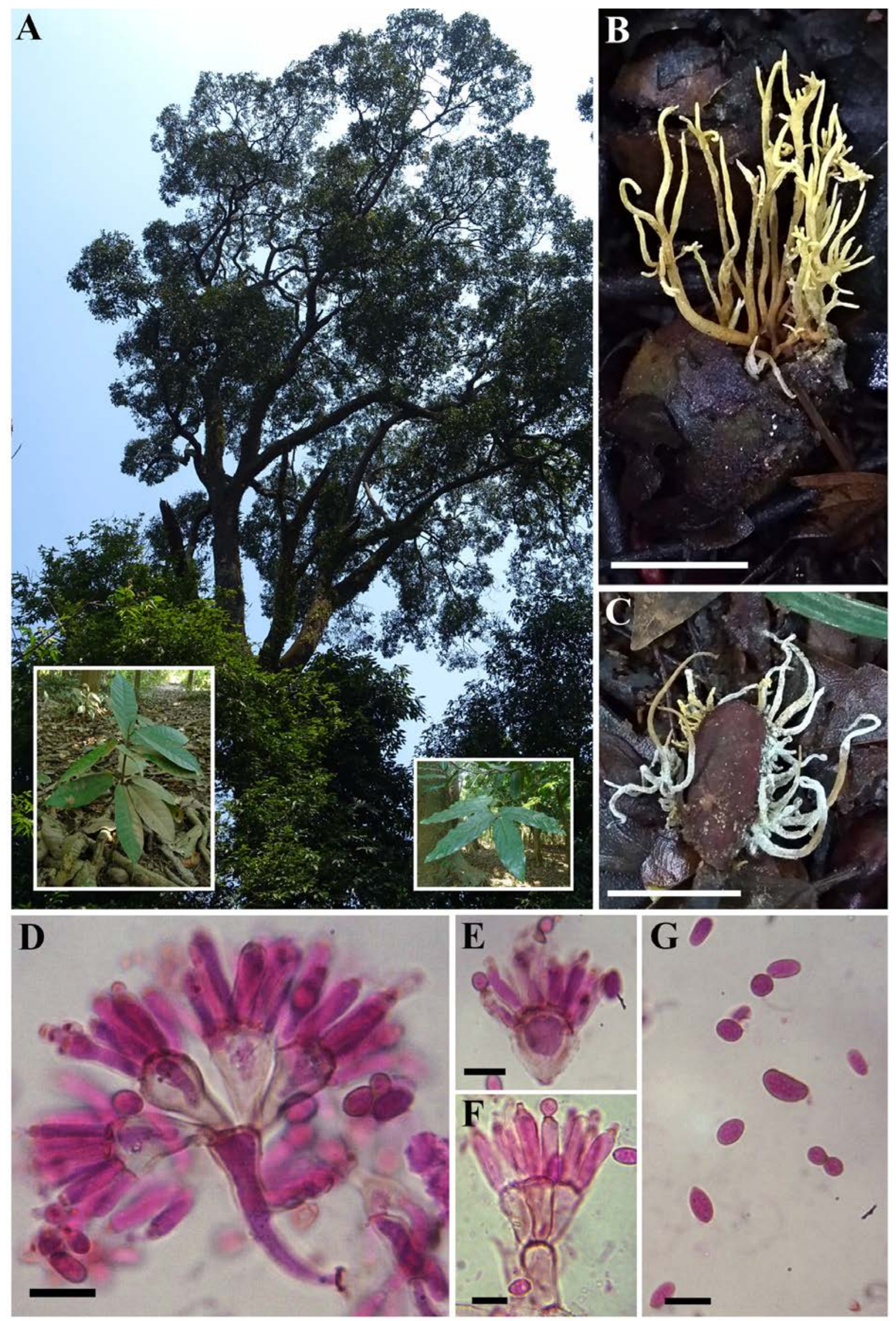

Fig. 1 - A Habit of Diospyros paniculata. B-C Synnemata of Penicilliopsis clavariiformis on D. paniculata fruit and seed respectively. D-F Conidiophore of $P$. clavariiformis showing ramuli, metulae and phialides. G Conidiospores. Scale bars: B, C = $5 \mathrm{~cm}, \mathrm{D}, \mathrm{E}, \mathrm{F}, \mathrm{G}=10 \mu \mathrm{m}$. 


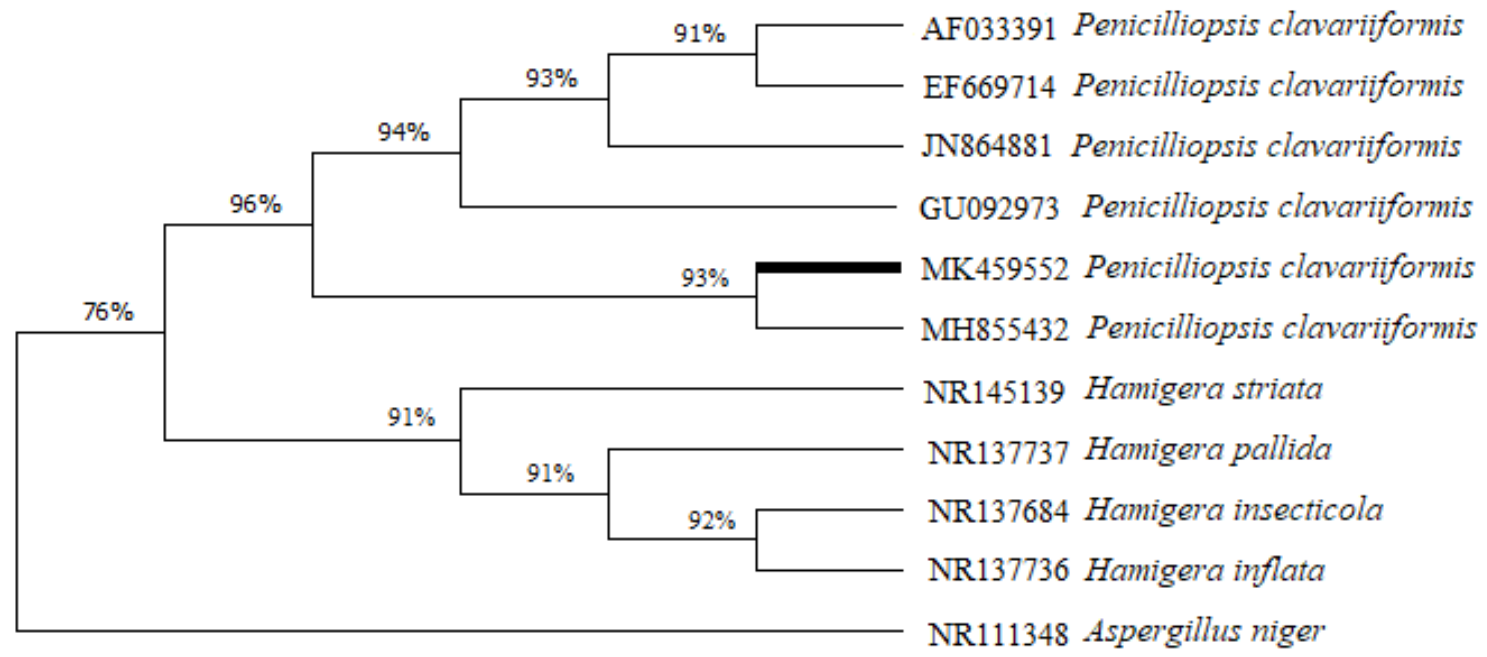

Fig. 2 - Maximum likelihood tree showing phylogenetic placement of $P$. clavariiformis. ML values are shown above the nodes. The newly generated ITS sequence of the strain from this study is shown in a thickened branch. GenBank accession numbers of all taxa are shown.

The clavarioid ascomata from Kerala were identified as belonging to Penicilliopsis clavariiformis Solms (Eurotiomycetes, Ascomycota) based on morphological characteristics and phylogenetic data. Penicilliopsis africana Samson \& Seifert shows similarity with the present specimen of $P$. clavariiformis in having stipitate stromata and bi- or terverticillate conidiophores. However, they differ in the presence of tentaculate synnemata, and smaller ascospores in $P$. africana (Samson \& Seifert 1985). Our collection also shows resemblance with $P$. bambusae Nag Raj \& Govindu, a species reported from Karnataka State, India on Bambusa species by Nag Raj \& Govindu (1970). According to the original description, P. bambusae has white synnemata which later turn to buff brown, whereas our collection possesses bright yellow coloured synnemata. Also, size of conidia of $P$. bambusae are slightly narrower $(5.5-10.5 \times 3.5-5 \mu \mathrm{m})$, when compared to that of present collection ((6) 7-9 (10) $\times 5-6 \mu \mathrm{m})$. Penicilliopsis bambusae have been reported only from Bambusa species and not from any other host plants. The molecular sequence generated here showed no similarity with any sequences of other species of Penicilliopsis.

Penicilliopsis clavariiformis was first described from Indonesia by Solms (1887) on the seeds of Diospyros macrophylla Blume. The species reproduce sexually by forming globose perithicia and asexually by forming conidiomata in their natural habitat (Oxford \& Raistrick 1940). Occurrence of this species on the seeds of D. discolour Willd. was reported by Hsieh \& Ju (2002) from Taiwan. Later, Douanla-Meli \& Langer (2007) reported this fungus from West Africa on the seeds of $D$. crassiflora Hiern. The chemical compound named penicilliopsin is responsible for the yellow coloration of the conidial form of P. clavariiformis (Oxford \& Raistrick 1940). According to Douanla-Meli \& Langer (2012), P. clavariiformis is an endophyte that produces many mycotoxins and penicilliopsin is one among them, capable of slowing down the proliferation of HIV. Stipe of $P$. clavariiformis contains a $\mathrm{pH}$ sensitive pigment which progressively accumulates in phialides and metulae with age (Samson \& Seifert 1985). In India, this species was first isolated as a salt tolerant fungus from mangroves (species unknown) by Kashyap et al. (2016). As per Kashyap et al. (2016), fungal genes such as Hsp98, Hsp60, HTB and RHO are responsible for the halotolerant property of $P$. clavariiformis. Apart from P. clavariiformis and P. bambusae, another species of Penicilliopsis reported from India is P. Indica K. Swapna \& Nagaveni. This species was isolated from seeds of Dysoxylum malabaricum Bedd. ex C. DC. by Swapna \& Nagaveni (2012) (as 'indicus'). However, the species was invalidly published (www.indexfungorum.org). According to the available reports, $P$. clavariiformis fruits specifically on Diospyros species and has not been 
reported from any other plant so far. This indicates an unknown association between $P$. clavariiformis and Diospyros species, which needs to be clarified in future studies. The present work presents the first record of this fungus on Diospyros paniculata. The species is also an addition to the mycobiota of Kerala.

\section{Acknowledgements}

We are grateful to Dr. A.K. Pradeep (Assistant Professor, Department of Botany, University of Calicut, Kerala, India) and Dr. K.P. Rajesh (Assistant Professor, PG \& Research Department of Botany, The Zamorin's Guruvayurappan College, Kerala, India) for identifying the host plant. Anjitha Thomas, Salna N. and Vinjusha N. acknowledge support from Kerala State Council for Science Technology and Environment in the form of research fellowships. The authors also thank the Chief Conservator of Forests \& Chief Wildlife Warden, Kerala, for permission for field work in the forest areas of Kerala.

\section{References}

Dhongade MJ, Masram SC. 2012 - Effect of Gum of Diospyros paniculata (Linn.) on histology of ovary of albino rat. Bionano Frontier 5, 169-171.

Douanla-Meli C, Langer E. 2007 - Record of Penicilliopsis clavariiformis (Ascomycota) on seeds of Diospyros crassiflora (Ebenaceae). In: Systematics and conservation of African plants. Proceedings of the 18th AETFAT Congress, Yaoundé, Cameroun, Royal Botanic Gardens. Pp123-132.

Douanla-Meli C, Langer E. 2012 - Diversity and molecular phylogeny of fungal endophytes associated with Diospyros crassiflora. Mycology 3, 175-187.

Gardes M, Bruns TD. 1993 - ITS primers with enhanced specificity for basidiomycetes application to the identification of mycorrhizae and rusts. Molecular Ecology 2: 113-118.

Doi: 10.1111/j.1365-294X.1993.tb00005.x.

Hsieh HM, Ju YM. 2002 - Penicilliopsis pseudocordyceps, the holomorph of Pseudocordyceps seminicola, and notes on Penicilliopsis clavariaeformis. Mycologia 94, 539-544.

Doi: 10.2305/IUCN.UK.2015 2.RLTS.T173931A1405117.en.

Indexfungorum. 2020 - http://www.indexfungorum.org/Names/Names.asp

Izumitsu K, Hatoh K, Sumita T, Kitade Y et al. 2012 - Rapid and simple preparation of mushroom DNA directly from colonies and fruiting bodies for PCR. Mycoscience 53, 396-401.

Jayasiri SC, Hyde KD, Ariyawansa HA, Bhat J. 2015 - The Faces of Fungi database: fungal names linked with morphology, phylogeny and human impacts. Fungal diversity 74, 3-18.

Kashyap PL, Rai A, Singh R, Chakdar H et al. 2016 - Deciphering the salinity adaptation mechanism in Penicilliopsis clavariiformis AP, a rare salt tolerant fungus from mangrove. Journal of basic microbiology 56, 779-91.

Kumar S, Stecher G, Li M, Knyaz C, Tamura K. 2018 - MEGA X: molecular evolutionary genetics analysis across computing platforms. Molecular Biology and Evolution 35, 1547-1549. Doi: 10.1093/molbev/msy096.

Nag Raj TR, Govindu HC. 1970 - Fungi of Mysore-IV. Sydowia 23, 110-119.

Oxford AE, Raistrick H. 1940 - Studies in the biochemistry of micro-organisms: Penicilliopsin, the colouring matter of Penicilliopsis clavariaeformis Solms-Laubach. Biochemical Journal 34, 790-803.

Samson RA, Seifert KA. 1985 - The ascomycete genus Penicilliopsis and its anamorphs. In: Advances in Penicillium and Aspergillus Systematics. Pp 397-428.

Doi: 10.1007/978-1-4757-1856-0_31.

Sinha BN, Bansal SK, Pattnaik AK. 2009 - Phytochemical and antimicrobial activity of extracts, fractions and betulin, 7-methyl juglone obtained from Diospyros paniculata. Journal of Natural Remedies 9/1, 99-102. 
Solms H. 1887 - Penicilliopsis clavariaeformis.einneuerjavanischerAscomycet. Annales du JardinBotanique de Buitenzorg 6, 53.

Swapna Priya K, Nagaveni HC. 2012 - A new species Penicilliopsis indicus, holomorph of Sarophorum on seeds of Dysoxylum malabaricum. Indian Phytopathology 65, 312-313.

Tamura K, Nei M. 1993 - Estimation of the number of nucleotide substitutions in the control region of mitochondrial DNA in humans and chimpanzees. Molecular Biology and Evolution 10, 512-526. Doi: 10.1093/oxfordjournals.molbev.a040023

Ved D, Saha D, Ravikumar K, Haridasan K. 2015 - Diospyros paniculata. The IUCN Red List of Threatened Species e: T173931A1405117.

White TJ, Bruns T, Lee SS, Taylor J. 1990 - Amplification and direct sequencing of fungal ribosomal RNA genes for phylogenetics. In: Innis, M.A., Gelfand, D.H., Sninsky, J.J., White, T.J. (eds) PCR Protocols: A Guide to Methods and Applications. Academic Press, New York. Pp 315-322. Doi: 10.1016/b978-0-12-372180-8.50042-1. 